\title{
Coupling hydrology, geochemistry and hydrodynamics towards rational management of discontinuous aquifers: application to the Ursuya massif (Basque Country, France)
}

\author{
J. JAUNAT ${ }^{1,2}$, F. HUNEAU ${ }^{1,2}$, A. DUPUY ${ }^{3}$, H. CELLE-JEANTON ${ }^{4,5,6} \&$ \\ P. LE COUSTUMER ${ }^{3}$ \\ 1 Université de Corse Pascal Paoli, Laboratoire d'Hydrogéologie, Corte, France \\ jaunat@univ-corse.fr \\ 2 CNRS, UMR 6134, SPE, Corte, France \\ 3 Université de Bordeaux, EA 4592 Géoressources \& Environnement, ENSEGID, France \\ 4 Clermont Université, Université Blaise Pascal, Laboratoire Magmas et Volcans, France \\ 5 CNRS, UMR 6524, LMV, 63038 Clermont-Ferrand, France \\ 6 IRD, R 163, LMV, 63038 Clermont-Ferrand, France
}

\begin{abstract}
The metamorphic massif of Ursuya (French Basque Country) is a strategic aquifer for the water supply of southwestern France. A multidisciplinary approach, conducted between 2009 and 2013, has led to understanding of the behaviour of this system made of discontinuous media. Isotopic and geochemical characteristics of rainwater were studied together with groundwater geochemistry, to delineate the water-rock interactions along the underground flowpaths. The chemical characteristics of groundwater, the residence times (less than 10 years to more than 50 years) and the associated mixing processes allow the achievement of a conceptual model of the groundwater flow. It highlights the role of the weathering profile from the point of view of mineralization as well as flowpaths. Finally, a quantitative approach shows highly heterogeneous hydrodynamic properties related to the weathering profile development. These results are synthesized and validated by a numerical model which forms the basis for rational management of the Ursuya aquifer in a region subject to a constant increase in water needs.
\end{abstract}

Key words groundwater; hard-rock aquifer; weathered profile; major ions; residence time; numerical model; Basque Country, France

\section{INTRODUCTION}

The French Basque Country has experienced marked demographic growth in recent decades leading to an important increase in water needs. The aquifer of the massif of Ursuya is one of the major groundwater resources of this region. A multidisciplinary approach has led to understanding of the behaviour of this system. The results help to progress the knowledge of discontinuous media and they provide support for rational management of this resource. The combination of intensive geochemical monitoring with hydrodynamic characterisation of the aquifer has led to a better knowledge of the different flow paths and so provides an essential tool for long-term management of this strategic resource.

\section{GENERAL SETTINGS}

Located in the northern Basque Country (southwestern France), $25 \mathrm{~km}$ from the city of Bayonne and from the Atlantic coast, the Ursuya Massif is the first relief of the Pyrenees from the west. The metamorphic formations (gneisses and paragneisses) of the Ursuya Massif are distributed between $40 \mathrm{~m}$ a.s.l. (bed of the Nive River) and $678 \mathrm{~m}$ a.s.l. (summit of the Ursuya Massif, $1^{\circ} 200 \mathrm{~W} ; 43^{\circ} 200 \mathrm{~N}$, Fig. 1). The study area is often covered by a more or less important layer of weathered material (frequently more than $10 \mathrm{~m}$ depth). The weathered layer is distributed between 100 and $350 \mathrm{~m}$ a.s.l. The fissured (non-weathered) layer is largely represented in the highest parts of the Ursuya Massif (above $350 \mathrm{~m}$ a.s.1.) and in the most incised valleys. The transition between these two layers is gradual with increasing weathering from the fissured to the weathered layer. This scheme constitutes the classical weathering profile observed in hard-rock aquifers (Lachassagne et al. 2008).

Between 1994 and 2003, 43 boreholes were drilled over the Ursuya Massif area to respond to the increasing water needs in the northwestern Basque Country. Of these boreholes, 34 were dry 


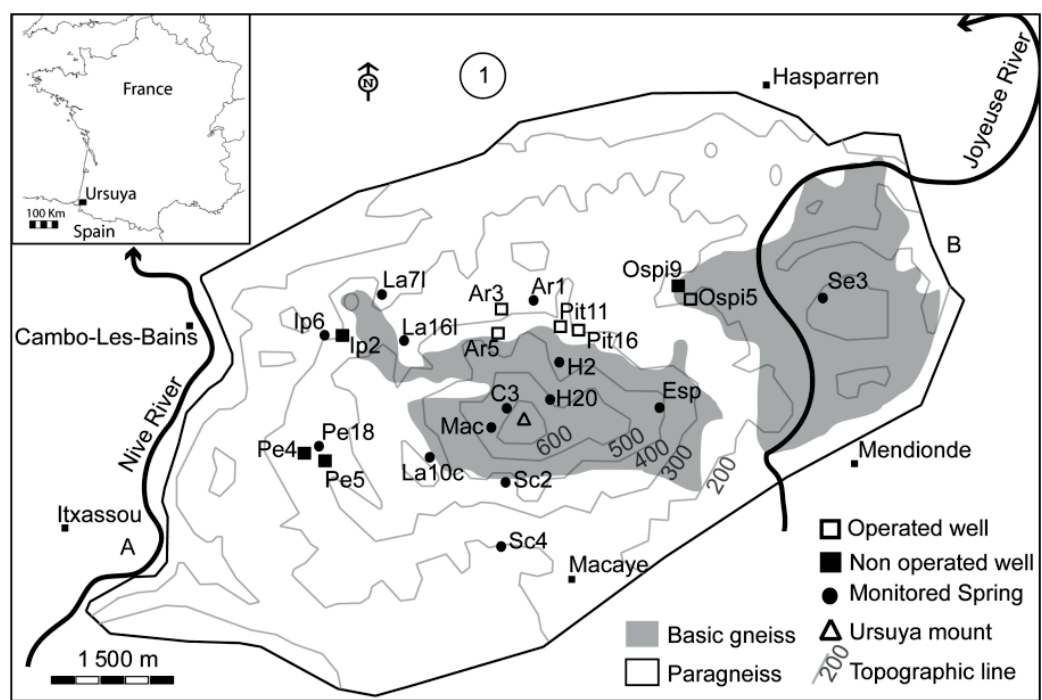

Fig. 1 Ursuya Mount topography and localisation of the sampling points.

or too unproductive to allow viable sustainable exploitation. Presently, only nine boreholes still exist in the study area, of which only five are operating. These boreholes have allowed many geological and hydrodynamic observations. In addition to the boreholes, 101 springs are exploited of more than 190 registered discharge points.

\section{SAMPLING AND ANALYTICAL METHODS}

Between 2009 and 2012, 14 sampling points were selected from the 190 springs for geochemical sampling (Fig. 1). The boreholes (Fig. 1) were also monitored, which allowed observation of the deeper water.

All the analyses were conducted at the laboratory of the EA 4592 Géoressources \& Environnement group at the University of Bordeaux. Major ions concentrations were determined by liquid chromatography Dionex 320 (IonPac CS16) for the cations and Dionex 1100 (IonPac AS11-HC) for the anions. The quality of the chemical analysis was checked using an electro neutrality condition up to $10 \%$, given the low mineralization of the studied waters. A sampling campaign for CFCs and $\mathrm{SF}_{6}$ analyses (used to estimate residence time of post-70 recharged groundwater) was conducted in summer 2011. Water was sampled in stainless-steel ampoules without air contact. The analyses were performed at the Geosciences Rennes Laboratory with the methodology described in Ayraud et al. (2008). The global uncertainty on age is estimated as \pm 2 years.

\section{RESULTS AND DISCUSSION}

\section{Groundwater quality}

While globally showing low mineralization, groundwaters show a high spatial variability of their geochemistry all over the study site (Jaunat 2012, Jaunat et al. 2013). The mean electrical conductivity ranges between 46 and $180 \mu \mathrm{S} \mathrm{cm}^{-1}$. Four water-types are observed in spring water: $\mathrm{Ca}-\mathrm{HCO}_{3}, \mathrm{Na}-\mathrm{HCO}_{3}, \mathrm{Na}-\mathrm{Cl}$ and $\mathrm{Ca}-\mathrm{Cl}$. The waters of the boreholes are all of $\mathrm{Ca}-\mathrm{HCO}_{3}$ water-type, except $\mathrm{Pe} 5$ and $\mathrm{Ar} 5$ that are of $\mathrm{Na}-\mathrm{Cl}$ and $\mathrm{Na}-\mathrm{HCO}_{3}$ water-type, respectively.

\section{Apparent ages}

Three models were used to convert the CFCs and $\mathrm{SF}_{6}$ concentrations into residence time values. Two hypothetical lump parametric models, a piston flow model (Maloszewski and Zuber 1996) and an exponential model (Maloszewski and Zuber 1996), were tested to determine the apparent water age. Mixing between two waters of different ages was also tested with a binary mixing model (Cook and Böhlke 2000). These models were selected on the basis of the available geological information 
and the adequacy of the four tracers (in case of no degradation or contamination) for the models. Indeed, given the high geologic and hydrodynamic heterogeneity of the hard-rock aquifer due to the weathering profile, different models can be used in the same system. In the fissured layer, the water flows are in unconfined conditions. Thus, dating of groundwater from this layer can only be performed with the exponential model. However, due to the definition of the weathered layer and to the application conditions of the models, any of the three models can be applied in this layer, according to the degree of weathering. Details on flow conditions and, therefore, on the proper dating model can also be obtained by borehole logging and pumping tests (Jaunat, 2012, Jaunat et al. 2012). Moreover, when the geological or hydrological data are insufficient, the use of four tracers is also helpful in the choice of model. Indeed, the four tracers may not give the same apparent age for an in valid model or the measured concentrations may not respond to the model characteristics. In this case, the model and age consistency for all tracers is validated. The piston flow model is the most suitable model for four springs (less than 10 years to 22 years) and five boreholes (10 to 42 years). Binary mixing model is the best model for two springs (mixing between $30 \%$ and $45 \%$ of a 25 -year end-member and a recent one) and four boreholes (5\% to $95 \%$ of recent water and an end-member of 25 years to older water). The exponential model is the most suitable for the four springs emerging from the fissured layer (mixing with water of mean residence time 11-15 years).

\section{Evidence of differential flowpaths}

It has been show that the geochemistry of groundwater and its transit time is highly variable all over the aquifer of Ursuya. This spatial variability can be attributed to the different geological material crossed by the water moving along its underground paths. The weathered profile observed in the massif of Ursuya is the origin of this spatial variability. It generates different flowpaths, and therefore varying residence times and geochemistry, according to the following scheme (Jaunat et al. 2012):

(a) In the fissured zone, when it is outcropping, only the exponential model is used and the apparent ages are close to each other, with mean residence times between 10 and 15 years. These values confirm the rapid groundwater flow and the unconfined conditions described in the definition of this layer. The geochemistry of groundwater from this flowpath is characteristic of a rapid transfer time with low mineralization.

(b) In the weathered zone, the piston flow model and binary mixing are applied. When the degree of weathering is high, mixing between groundwater from the weathered and fissured layers is not allowed and flows occur only in the underlying fissured one. The piston flow model correctly represents this flow pathway. The geochemistry and the apparent age are based on hydrodynamic characteristics of the weathered layer: the greater the degree of weathering, the less the porosity and hydraulic conductivity and the longer the residence time. The mineralization here is positively correlated with apparent ages because of time dependent water-rock interactions.

(c) Conversely, the binary mixing model is a good approximation of mixing between weathered and fissured layer water. The apparent ages calculated with the binary mixing model in Ursuya Massif are the result of mixing between recent waters flowing in a poorly developed weathered layer and oldest ones flowing in the underlying fissured layer after a long transit. In this case, the global mineralization depends on the proportion of the two end members.

\section{TOWARDS SUPPORT IN THE MANAGEMENT OF THE RESOURCE}

\section{From a conceptual model to a numerical one}

It has been clearly demonstrated that the high spatial variability observed in the geochemical characteristics of the water is mainly due to the different materials crossed by the groundwater. The conceptual model previously described was therefore a basis for the computation of a numerical model summarizing the knowledge acquired during this study, especially for the computation of the geometry (Fig. 2).

The numerical translation of this conceptual model has been realized with the Feflow code 6.0 (Finite Element Subsurface Flow and Transport Simulation System; Trefry and Muffels 2007). The 
surface of the aquifer was discretized using a triangular mesh of 74777 elements (Fig. 2(b)). The vertical discretization is represented through five layers of calculation (weathered layer, transition layer, highly fissured layer, lightly fissured layer and non-fissured bedrock; Fig. 2(a)).

Potential groundwater flows and exchanges through the limits of the aquifer have been computed with fixed hydraulic heads (Dirichlet-type boundary conditions). The relationships between the surface flow network and the sub-surface were simulated by Cauchy-type boundary conditions. These boundary conditions allow simulation of interactions between streams and groundwater, through a layer that is more or less poorly permeable.
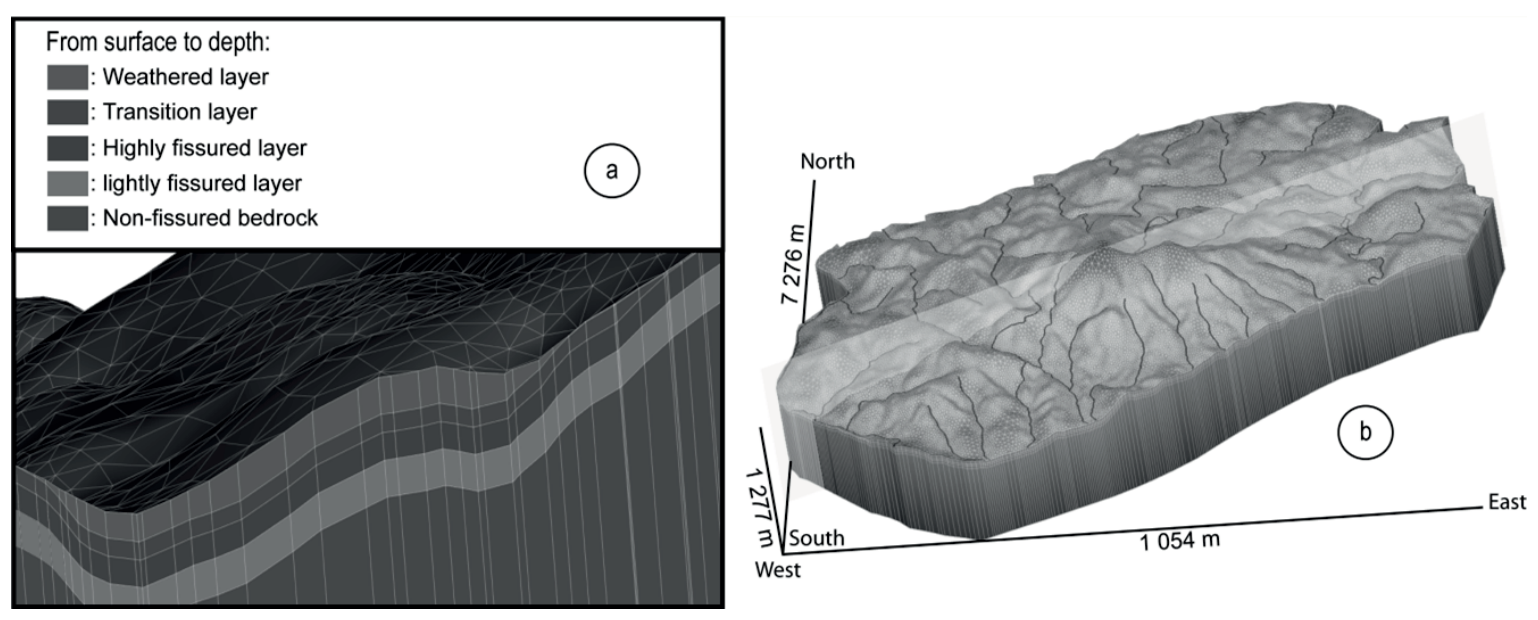

Fig. 2 Geometry of the numerical model (a factor of 2 is applied to the vertical axis).

The data required for the model calibration consist primarily of recharge, pumping and hydraulic head data. This dataset was precisely recorded on the massif of Ursuya since July 2009. Therefore, after a first step of calibration in steady state, the numerical model was calibrated over a period of three years between July 2009 and July 2012. Because of the frequency of the measurements, a weekly discretization was chosen. Given the reactivity of the system, these weekly time steps can indicate with sufficient detail the different states during the year. The calibration was validated by calculation of the average residual (average difference between observed and simulated values); with a value about $0.89 \mathrm{~m}$ in steady state and $-0.3 \mathrm{~m}$ in transient state, the representativeness of the model has been validated.

\section{Hydrodynamic properties}

To simulate groundwater flow as close as possible to reality, the hydraulic conductivity and storage values used in the model were based on data from pumping tests and values from the literature for similar systems. These values were then adjusted during the calibration process in the steady and transient states, in particular to clarify the influence of discontinuities on groundwater flow within the Ursuya Massif.

The values of hydraulic conductivity obtained after the calibration are displayed in Fig. 3. These ranges of conductivity are consistent with the data given in the literature (especially Dewandel et al. 2006) for the five modelled horizons.The numerical model has revealed the geographical position of preferential flow zones, in particular along the principal discontinuities. In a context of increasing water needs, this information is crucial for the establishment of new boreholes, which should be installed along the high permeability zones, preferentially in the fissured layer.

\section{Long-term simulations}

The water resource management has to be undertaken with a long-term vision. For this purpose, assessing the impacts of climate change on groundwater flow may be necessary. The numerical 


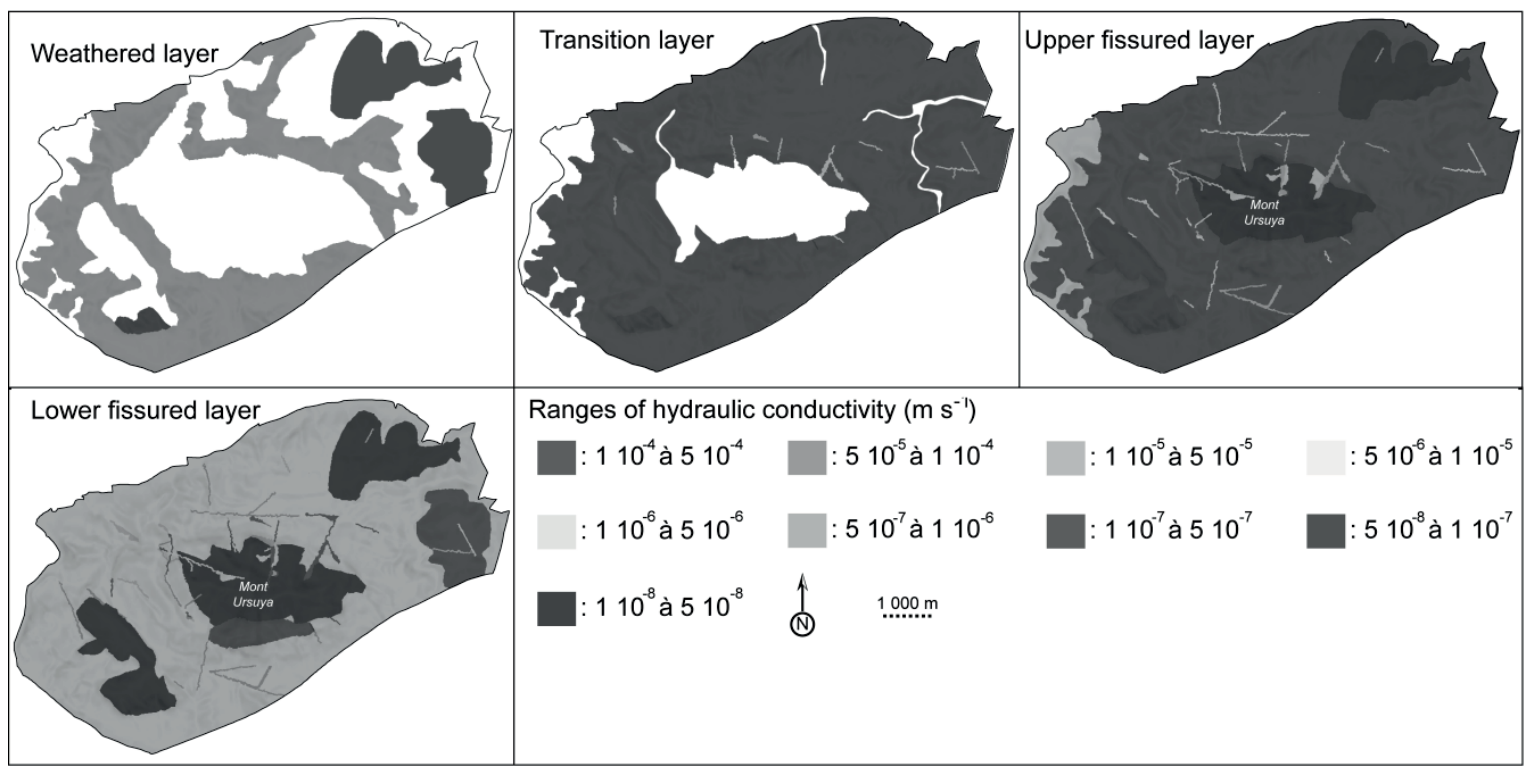

Fig. 3 Maps of hydraulic conductivity of the five horizons after calibration (not shown: hydraulic conductivity of bedrock horizon is homogeneous with a value about $1 \times 10^{-8} \mathrm{~m} \mathrm{~s}^{-1}$ ).

model of the Ursuya aquifer allows estimation of the potential evolution of the groundwater resources in relation to climate evolution.

For these simulations, the rainfall dataset from the SCRATCH2010 models (produced by CERFACS, European Centre for Research and Advanced Training in Scientific Computation; Pagé and Terray 2010) was used, with a spatial resolution of $8 \mathrm{~km}$. These data are disaggregated from the ARPEGE model V4.6 (Action Research Small Scale Large Scale) produced by CNRM (National Meteorological Centre of Research). Predictive simulations were performed over a period of 49 years, between 2001 and 2050, with a monthly time step. Groundwater exploitation was also introduced. Average monthly volumes were calculated using the three years of available data, these being representative of normal years. These volumes were repeated identically for the 49 years of simulation. Without precise predictive demographic data, this treatment seems appropriate for the evaluation of the impact of the actual exploitation on the resource.

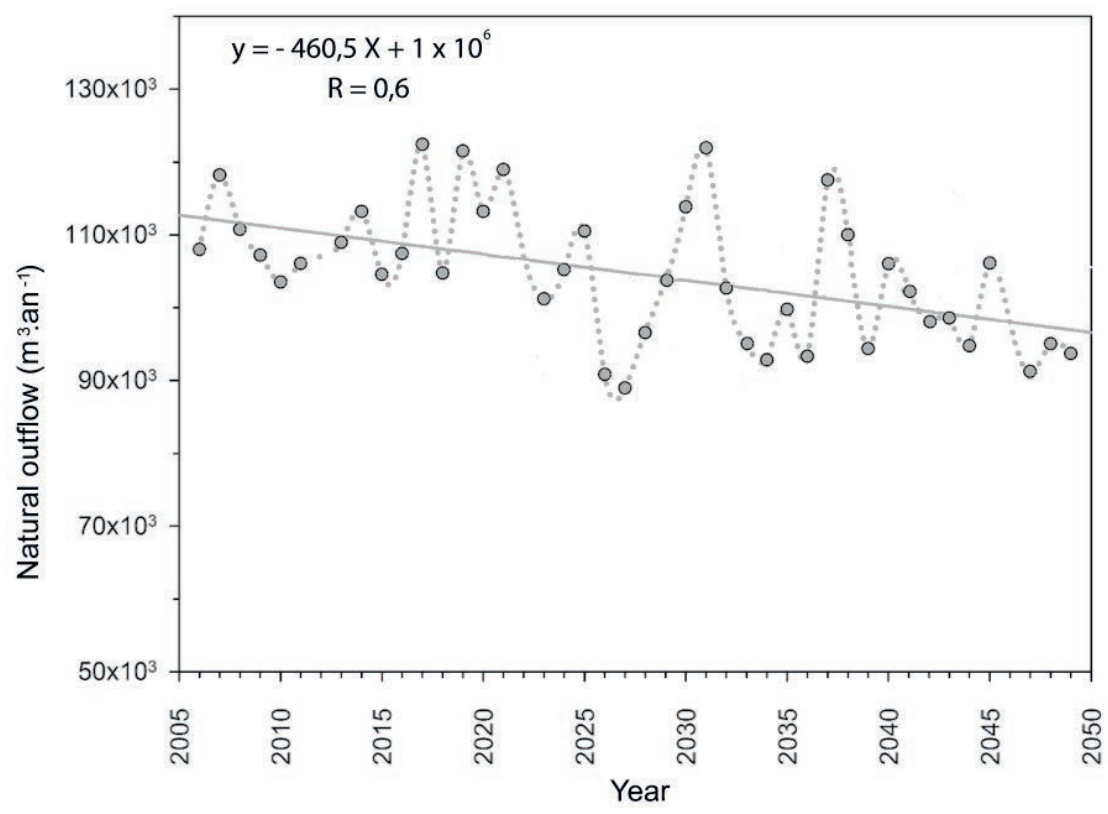

Fig. 4 Natural annual outflows simulated between 2005 and 2050. 
The estimated rainfall decrease is relatively low for the next 50 years at the study site; the same tendency is expected for the global hydraulic heads. A small significant decrease is observed (approximately $1 \mathrm{~mm}$ year $^{-1}$ ). However, the decrease in the natural outflow through the surface network (springs and streams), is estimated to $-460 \mathrm{~m}^{3} \mathrm{year}^{-1}$, that is to say a reduction in the annual volume of more than $20000 \mathrm{~m}^{3}$ in 50 years (Fig. 4). Indeed, besides a small rainfall decrease, its effect on the whole area could be significant. However, this result has to be put in the context of the actual exploited volumes from this aquifer $\left(1.5\right.$ million $\mathrm{m}^{3}$ year ${ }^{-1}$ from the springs and 1.8 million $\mathrm{m}^{3}$ year $^{-1}$ from boreholes). The calculated 50-year decrease corresponds to only $1.3 \%$ of the exploited volumes of spring water and $1.1 \%$ of the total volume collected.

Finally, this long-term simulation, and the low outflow decrease calculated, has to be carefully considered, but the climate change does not seem to be a crucial parameter in the five future decades for the Ursuya aquifer. However, longer simulations could show more worrying results.

\section{CONCLUSIONS}

In a context of increasing demand for drinking water, the sustainability of the strategic groundwater resource of the massif of Ursuya was suspected to be compromised. It was thus necessary to rapidly provide a rational mode of exploitation, in accordance with the potential of the aquifer and the water needs. To this purpose, multi-hydrological methods allowed better understanding of the behaviour of this aquifer, and particularly discrimination of the different flow paths. In a second step, these results were used for the construction of a numerical hydrodynamic model. This has clearly highlighted: (a) favourable zones where new boreholes should be implemented, (b) the possibility of increasing the water sampling, in a rational way, without endangering the resource, and (c) the very low sensitivity of this aquifer to projected climate evolution in the Basque Country, until 2050. These results demonstrate that precise knowledge of the functioning of an aquifer is a prerequisite for a rational management of the groundwater resource. Furthermore, the coupling of hydrologic, geochemical and hydrodynamic data offers a global vision of the studied system.

\section{REFERENCES}

Ayraud, V., et al. (2008) Compartmentalization of physical and chemical properties in hard-rock aquifers deduced from chemical and groundwater age analyses. Applied Geochemistry, 23, 2686-2707.

Cook, P. G. and Böhlke, J., (2000) Determining timescales for groundwater and solute transport. In Cook, P.G., and Herczeg, A., eds., Environmental tracers in subsurface hydrology. Boston, Mass., Kluwer Academic Publishers, 1-30.

Dewandel, B., et al. (2006) A generalized 3-D geological and hydrogeological conceptual model of granite aquifers controlled by single or multiphase weathering. Journal of Hydrology 330, 260-284.

Jaunat. J. (2012) Caractérisation des écoulements souterrains en milieu fissuré par approche couplée hydrologie-géochimiehydrodynamisme - Application au massif de l'Ursuya (Pays Basque, France). thèse de doctorat, Université Michel de Montaigne - Bordeaux 3, 344 p.

Jaunat, J., et al. (2012) Hydrochemical data and groundwater dating to infer differential flowpaths through weathered profiles of a fractured aquifer. Applied Geochemistry 27, 2053-2067, doi: 10.1016/j.apgeochem.2012.06.009.

Jaunat J., et al. (2013) Characterization of the input signal to aquifers in the French Basque Country: emphasis on parameters influencing the chemical and isotopic composition of recharge waters. Journal of Hydrology 496, 57-70, doi:10.1016/j.jhydrol.2013.05.026.

Lachassagne, P., et al. (2008) Recent improvements in the conceptual model of hard rock aquifers and its application to the survey, management, modelling and protection of groundwater. In: Groundwater and Climate in Africa ed. by R. Taylor, et al. (Proceedings of the Kampala Conference). IAHS Publ. 334, 250-256.

Maloszewski, P. and Zuber, A. (1996) Lumped parameter models for the interpretation of environmental tracer data. Manual on mathematical models in isotope hydrogeology, IAEA-TECDOC-910, 9-58.

Pagé, C. and Terray, L. (2010) Nouvelles projections climatiques à échelle fine sur la France pour le 21ème siècle: les scénarii SCRATCH2010. CERFACS Technical Report TR/CMGC/10/58, Toulouse, France, 3 p.

Trefry, M. G. and Muffels, C. (2007) FEFLOW: A Finite-element ground water flow and transport modeling tool. Ground Water $45,525-528$. 